\title{
MENINGKATKAN HASIL BELAJAR LOMPAT JAUH MELALUI GAYA MENGAJAR INKLUSI BAGI MAHASISWA PJKR FKIP UNIVERSITAS SURYAKANCANA CIANJUR
}

\author{
Eka Yanuar Putra
}

Pendidikan Jasmani Kesehatan dan Rekreasi

Fakultas Keguruan dan Ilmu Pendidikan, Universitas Suryakancana

ekayanuar@gmail.com

\begin{tabular}{l}
\hline Info Artikel \\
\hline Sejarah Artikel: \\
Diterima Oktober 2018 \\
Disetujui November 2018 \\
Dipublikasikan Desember \\
2018
\end{tabular}

Abstrak

Tujuan penelitian ini adalah untuk mengetahui upaya meningkatkan hasil belajar lompat jauh melalui gaya mengajar inklusi. Penelitian ini dilakukan di PJKR FKIP Universitas Suryakancana Cianjur. Untuk dapat menjawab permasalahan penelitian, maka dalam pelaksanaan penelitian ini menggunakan metode eksperimen. Untuk dapat menjawab permasalahan penelitian, maka dalam pelaksanaan penelitian ini menggunakan metode eksperimen. Karena penelitian merupakan interaksi, desain yang paling tepat digunakan dalam penelitian ini adalah desain faktorial. Penelitian ini dilaksanakan di FKIP PJKR Universitas Suryakancana sebagai tempat penelitian. Berdasarkan hasil uji lanjut dengan menggunakan uji Tukey, dengan taraf signifikansi $\partial=0,05$ diperoleh harga $q_{\text {hitung }}$ sebesar $=3,247>q_{\text {tabel }}$ sebesar $=2,86$ maka dengan demikian $H_{0}$ ditolak. Dengan demikian dapat disimpulkan bahwa penelitian secara keseluruhan hasil hasil belajar lompat jauh yang belajar dengan gaya mengajar inklusi, lebih baik daripada yang belajar dengan gaya mengajar latihan secara keseluruhan teruji kebenarannya.
Keyword: Hasil Belajar,

Lompat Jauh, Gaya

Mengajar Inklusi

\section{Abstrack}

The purpose of this study was to determine efforts to improve learning outcomes of long jump through inclusive teaching styles. This research was conducted at PJKR FKIP Suryakancana Cianjur University. To be able to answer the research problem, the implementation of this research uses the experimental method. To be able to answer the research problem, the implementation of this research uses the experimental method. Because research is interaction, the most appropriate design used in this study is factorial design. This research was conducted at FKIP PJKR Suryakancana University as a place of research. Based on the results of further tests using the Tukey test, with a significance level $=0.05$, the qhitung value $=3.247>$ qtable $=2.86$, thus $H O$ is rejected. Thus it can be concluded that the overall research results of long jump learning outcomes that learn with inclusive teaching style, are better than learning with teaching style overall practice tested its truth 
Meningkatkan Hasil Belajar Lompat Jauh Melalui Gaya Mengajar Inklusi Bagi Mahasiswa Pjkr Fkip Universitas Suryakancana Cianjur

(C) 2018 Universitas Suryakancana

$\square$ Alamat korespondensi:
E-mail:
Adirahadian@unsur.ac.id

\section{PENDAHULUAN}

Pendidikan Jasmani Olahraga Kesehatan dan Rekreasi merupakan bagian integral dari pendidikan, bertujuan untuk mengembangkan aspek kebugaran jasmani, keterampilan gerak, keterampilan berfikir kritis, keterampilan sosial, penalaran, stabilitas emosional, tindakan moral, aspek pola hidup sehat dan pengenalan lingkungan bersih melalui aktivitas jasmani, olahraga kesehatan dan rekreasi terpilih yang direncanakan secara sistematis dalam rangka mencapai tujuan pendidikan nasional.

Pendidikan jasmani, Olahraga, kesehatan, dan rekreasi merupakan media untuk mendorong pertumbuhan fisik, perkembangan psikis, keterampilan motorik, pengetahuan dan penalaran, penghayatan nilai-nilai (sikap, mental, emosional, sportivitas, spiritual, sosial), serta pembiasaan pola hidup sehat yang bermuara untuk merangsang pertumbuhan dan perkembangan kualitas fisik dan psikis yang seimbang. Pendidikan jasmani menekankan aspek pendidikan yang bersifat menyeluruh antara lain kesehatan, kebugaran jasmani, keterampilan berfikir
e-ISSN : 2721-7175 (online)

p-ISSN : 2089-2341 (cetak) kritis, stabilitas emosional, keterampilan sosial, penalaran dan tindakan moral, yang merupakan tujuan pendidikan pada umumnya. Atau secara spesifik melalui pembelajaran pendidikan jasmani, siswa melakukan kegiatan berupa permainan (game), dan berolahraga yang disesuaikan dengan pertumbuhan dan perkembangan anak. Meskipun demikian, unsur prestasi dan kompetisi juga terdapat di dalamnya dan dimanfaatkan sebagai alat pendidikan (Depdiknas, $2002: 5$ )

Keterampilan lompat merupakan salah satu materi dari nomor lompat dalam cabang olahraga atletik yang harus pula disajikan di Pendidikan Jasmani kesehatan dan rekreasi. Jenis lompat yang umumnya dilaksanakan adalah lompat tinggi, lompat jauh, lompat jangkit, dan lompat galah., yang yang harus ditempuh oleh mahasiswa PJKR FKIP Universitas Suryakancana.

Lompat jauh adalah satu jenis keterampilan yang bertujuan untuk mencapai lompatan yang sejauh-jauhnya. Prinsip dasar lompat jauh adalah membangun awalan yang secepatcepatnya dan melakukan tolakan yang 


\section{8 | Eka Yanuar Putra}

Meningkatkan Hasil Belajar Lompat Jauh Melalui Gaya Mengajar Inklusi Bagi Mahasiswa Pjkr Fkip Universitas Suryakancana Cianjur sekuat-kuatnya ke arah depan-atas dengan Gaya mengajar Inklusi adalah satu kaki untuk meraih ketinggian yang optimal saat melayang sehingga menghasilkan jarak lompatan yang sejauhjauhnya.

Hasil lompatan yang optimal, diperlukan kondisi fisik dan teknik yang memadai. Pengaruh kondisi fisik akan terlihat pada kecepatan pelompat ketika melakukan awalan dan tolakan sangat pada lompat jauh. Sedangkan keserasian gerak awalan dan tolakan sangat bergantung pada kemampuan tekniknya. Apabila kecepatan lari awalan dan kekuatan menolak ini dilakukan dengan teknik awalan dan tolakan yang baik.

Pelaksanaan pembelajaran lompat jauh merupakan yang harus dilakukan oleh para mahasiswa pendidikan jasmani kesehatan dan rekreasi, maka perlu untuk ditingkatkan hasilnya terutama dalam kegiatan pembelajaran sehingga menjadi bekal bagi para mahasiswa ketika mengajarkan lompat jauh di sekolah, karena mata pelajaran pendidikan jasmani khusunya atletik sudah diajarkan di Sekolah Dasar dimulai dari kelas I (satu) sampai kelas VI (enam), sehingga siswa sudah mempunyai modal dalam belajar atletik termasuk lompat jauh.

Sejalan dengan itu, maka untuk mengajarkan teknik lompat dalam pembelajaran pendidikan jasmani, diperlukan gaya mengajar yang tepat dan mudah diterapkan kepada siswa, sehingga teknik gerakan lompat lompat jauh dapat dikuasai siswa dengan baik dan benar. 


\section{9 | Eka Yanuar Putra}

Meningkatkan Hasil Belajar Lompat Jauh Melalui Gaya Mengajar Inklusi Bagi Mahasiswa Pjkr Fkip Universitas Suryakancana Cianjur Tujuan utama dalam lompat tinggi gerakan menolak, teknik gerakan badan adalah membawa pusat massa badan setinggi mungkin, sehingga melewati mistar yang dipasang. Seperti yang dikemukan Yusuf; Tujuan dari lompat tinggi ini adalah untuk mencapai jarak lompatan yang setinggi-tingginya (Yusuf Adisasmita, 1992 : 81). Untuk itu, diperlukan suatu rangkaian gerak yang khas agar tujuan tersebut dapat dicapai. Selain itu, juga diperlukan matras busa yang tebal, yang sangat bermanfaat dalam rangka memperkecil resiko tejadinya cedera.

Dauer dan Pangrahi berpendapat, bahwa lompat tinggi adalah suatu aktivitas yang diawali dengan gerakan berlari untuk mengambil awalan dengan patokan ganjil, yaitu bisa tiga langkah, bisa lima langkah ataupun tujuh langkah. Serta diikuti dengan langkah-langkah yang akhir panjang dan cepat, dengan titik berat badan condong kebelakang, dilanjutkan dengan gerakan menolak dengan satu kaki yang kuat dipakai sebagai kaki tumpu (kebanyakan kaki kanan). Dan diakhiri dengan gerakan sikap badan sewaktu posisi melayang diatas mistar, serta diakhiri dengan gerakan sikap badan pada waktu jatuh atau pada saat mendarat (Dauer, 1989 : 159).

\section{Selanjutnya}

Nossek

mengemukakan, pencapaian hasil lompatan yang lebih baik hanya dapat dicapai melalui pemantapan koordinasi gerak teknik lompat tinggi yang meliputi: teknik gerakan lari untuk awalan, teknik pada saat melayang melewati mistar, dan teknik sikap badan waktu mendarat yang masing-masing mempunyai yang masingmasing mempunyai seluk-beluk dan mekanisme sendiri (Nossek, 1982 : 346).

Dari beberapa pendapat di atas, dapat disimpulkan bahwa lompat jauh adalah aktivitas yang dimulai dari teknik gerakan lari untuk awalan, teknik gerakan tolakan atau tumpuan, teknik badan saat melayang, dan diakhiri dengan teknik gerakan pada saat mendarat.

Keberhasilan seorang pelompat jauh adalah jauhnya jarak lompatan, hal ini dipengaruhi oleh beberapa faktor, antara lain: (1) lari saat pengambilan awalan, (2) ketepatan dan kekuatan saat melakukan tolakan, (3) penguasaaan pada saat badan melayang, dan (4) posisi badan pada saat mendarat.

\section{Hasil Belajar Lompat Jauh}

Hasil belajar lompat jauh adalah kemampuan siswa dalam melakukan teknik gerakan lompat jauh, yang ditandai dengan kebenaran gerakan awalan, tolakan, saat melayang, dan pada saat mendarat. Yang siswa lakukan setelah mereka menerima pengalaman belajar nomor lompat jauh. .

Jadi hasil belajar lompat jauh adalah kemampuan dalam melakukan gerakan lompat jauh yang terdiri dari teknik gerakan lari untuk awalan, teknik gerakan saat menolak, teknik grekan saat badan melayang dan diakhiri dengan 


\section{0 | Eka Yanuar Putra}

Meningkatkan Hasil Belajar Lompat Jauh Melalui Gaya Mengajar Inklusi Bagi Mahasiswa Pjkr Fkip Universitas Suryakancana Cianjur teknik gerakan saat mendarat, merupakan skor. Yang dilakukan testee.

Dari ke empat indikator tersebut masing-masing dikembangkan menjadi tiga buit diskriptor. Dari setiap diskriptor masing-masing mempunyai rentang skor antara tiga dampai satu (3-1). Yaitu skor 3 diskriptor terpenuhi (sangat sempurnna), skor 2 hanya terpenuhi dua skriptor (sempurna), dan skor 1 hanya satu diskriptor (kurang sempurna).

\section{Gaya Mengajar}

Salah satu cara untuk mengajarkan materi pendidikan jasmani agar dapat berhasil dengan baik antara lain dengan cara menggunakan gaya mengajar. Karena gaya mengajar merupakan pedoman khusus untuk struktur episode belajar atau tahapan pelajaran (Adisasmita, 1997:1). Gaya mengajar adalah merupakan spektrum gaya untuk menjembatani antara pokok bahasan dan belajar (Mosston, 1994:316). Istilah gaya mengajar ini khusus dipergunakan untuk mengajar materi praktek pendidikan jasmani, karena di dalam gaya mengajar tersebut terurai jelas tentang bagaimana peranan dosen dan mahasiswa dalam proses pembelajaran pendidikan jasmani.

Berdasarkan pendapat-pendapat di atas, dapat dikemukakan bahwa gaya mengajar adalah pedoman mengajar yang disusun oleh dosen secara khusus untuk melaksanakan pembelajaran pokok bahasan materi pendidikan jasmani. Dalam proses belajar mengajar yang menggunakan gaya mengajar, dosen dapat memberikan instruksi secara langsung maupun instruksi tidak langsung kepada siswa tentang cara belajar (Joyce, 1989:31). Neil J. Dogherty mengemukakan bahwa untuk mempermudah proses pembelajaran dalam pokok bahasan materi pendidikan jasmani, siswa dapat dibagi dalam kelompok maupun perorangan (Neil J, 1979:10). Di dalam pelaksanaan gaya mengajar, setiap perilaku yang ditampilkan oleh dosen merupakan hasil pengambilan keputusan. Keputusan tersebut di ambil berdasarkan pada pokok bahasan yang akan diajarkan, dan di dalam melaksanakan keputusan tersebut dengan cara dibagi berdasarkan dalam tingkatan; (1) sebelum pertemuan (pre-impact), (2) saat pertemuan (impact), dan (3) sesudah pertemuan (post-impact) (Mossston, 1994:5-8). Pre-impact adalah keputusan-keputusan yang diambil sebelum pelajaran dimulai yaitu dosen menyiapkan materi pelajaran yang akan disajikan. Impact adalah keputusankeputusan yang diamabil pada saat pembelajaran berlangsung. Sedangkan post-impact adalah keputusan yang diambil setelah siswa melaksanakan tugas belajar atau pada saat evaluasi dilakukan.

Secara keseluruhan gaya mengajar yang dapat dipergunakan dalam proses pembelajaran praktek pendidikan jasmani adalah: (1) gaya mengajar komando (commando style), (2) gaya mengajar latihan (practice style), (3) gaya mengajar resiprokal (reciprocal style), (4) gaya 


\section{1| Eka Yanuar Putra}

Meningkatkan Hasil Belajar Lompat Jauh Melalui Gaya Mengajar Inklusi Bagi Mahasiswa Pjkr Fkip Universitas Suryakancana Cianjur mengajar periksa diri (self check style), (5) pelajaran dapat diberikan secara jelas dan gaya mengajar inklusi (inclussion style), (6) gaya mengajar penemuan terpimpin (guided discovery style), (7) gaya mengajar divergen (divergent style), dan (8) gaya mengajar program individual (learned desigh style). Dari keseluruhan gaya mengajar yang dipaparkan tersebut di atas, maka dalam penelitian ini yang akan digunakan adalah dua gaya mengajar untuk dijadikan bahan penelitian yaitu gaya mengajar inklusi (inclusion style) dan gaya mengajar latihan (practice style).

\section{Gaya mengajar Inklusi}

Gaya mengajar inklusi adalah pedoman mengajar yang diapaki oleh dosen yang menyajikan materi pelajaran secara keseluruhan yang secar rinci dipaparkan tingkat kesulitannya. Tujuannya adalah agar siswa kreatif dan mendapatkan kemudahan dalam mempelajari suatu keterampilan gerak, sebab siswa diberi kebebasan untuk memilih dan menentukan pada tingkat kesulitan mana mahasiswa mulai belajar, serta diberi kebebasan pula untuk menentukan berapa kali mahasiswa harus mengulani gerakan dalam mempelajari suatu teknik gerakan dalam setiapa kali mahasiswa harus mengulani gerakan dalam mempelajari suatu teknik gerakan dalam setiaptemuan (Mosston, 1994:114120).

Keuntungan menyajikan bahan secara keseluruhan terlebih dahulu adalah informasi dan konsep tentang materi

keterampilan (Harsono, 1988:141). Pendapat lain menyatakan bahwa apabila gerakan sifatnya sederhana lebih baik diajarkan secara menyeluruh (Peter J, 1999:50), dan apabila terdapat hubungan yang erat antara unsur gerakan sebaiknya menggunakan cara keseluruhan (Sugyanto, 1991:369).

\section{Berdasarkan pemaparan-} pemaparan di atas, maka dikemukakan bahwa gaya mengajar inklusi adalah pedoman mengajar yang disusun oleh dosen secara khusus yang isinya mencakup keseluruhan dari materi yang akan diajarkan. Disajikan dengan tingkattingkat kesulitan yang berbeda dalam mata pelajaran praktek pendidikan jasmani.

$$
\text { Keuntungan menggunakan }
$$

perlakukan gaya mengajar inklusi dalam praktek pembelajaran pendidikan jasmani khususnya dalam mempelajari gerkan teknik lompat jauh adalah: (1) mahasiswa telah mempunyai gambaran secara keseluruhan tentang cara mempelajari gerakan tekinik lompat jauh melalui penjelasan dosen dan lembaran tugas sehingga siswa mudah untuk memilih dan menentukan di mana ia mulai belajar, (2) mahasiswa memperoleh penjelasan dari dosen tentang cara memilih tingkatantingkatan tugas yang akan dipelajarinya, (3) mahasiswa bebas memilih materi pelajaran, (4) mahasiswa dapat membagi waktu pada materi mana memerlukan banyak waktu untuk mempelajari materi 


\section{2| Eka Yanuar Putra}

Meningkatkan Hasil Belajar Lompat Jauh Melalui Gaya Mengajar Inklusi Bagi Mahasiswa Pjkr Fkip Universitas Suryakancana Cianjur yang sulit dan materi yang mudah.

Sedanfgkan kekurangan dari menggunakan perlakuan gaya mengajar inklusi dalam praktek pembelajaran pendidikan jasmani dalam mempelajari gerakan teknik lompat jauh adalah: (1) mahasiswa kurang akan serius dalam belajar, karena penjelasan dosen siswa belajar sendiri, (2) sulit mengontrol bagi mahasiswa yang berkemampuan kurang.

Apabila dilihat tugas dosen dan mahasiswa sebelum pertemuan (preimpact), pertemuan (impact) dan setelah pertemuan (post-impact), serta keuntungan dan kekurangan menggunakan perlakuan gaya mengajar inklusi ini, maka dapat diduga keberhasilan belajar gerakan teknik lompat jauh dapat diukur.

\section{METODE PENELITIAN}

Untuk dapat menjawab permasalahan penelitian, maka dalam pelaksanaan penelitian ini menggunakan metode eksperimen. Karena penelitian merupakan interaksi, desain yang paling tepat digunakan dalam penelitian ini adalah desain faktorial. Penelitian ini dilaksanakan di FKIP PJKR Universitas Suryakancana sebagai tempat penelitian.

\section{HASIL PENELITIAN}

Hasil perhitungan Analisis Varians tentang perbedaan hasil belajar lompat jauh antara gaya mengajar inklusi dibandingkan dengan gaya mengajar latihan, secara keseluruhan sebagiman terlihat pada tabel di atas terlihat bahwa $\mathrm{F}$ hitung antara kolom $\mathrm{FA}=5,27>\mathrm{F}_{\text {tabel }}$

sebesar $=4,11$, atau $\mathrm{F}_{0}=5,27>\mathrm{F}_{t}=4,11$; maka dengan demikian $H_{0}$ ditolak. Kesimpulan bahwa, secara keseluruhan terdapat perbedaan nyata hasil belajar lompat jauh antara yang belajar dengan gaya mengjar inklusi dan yang belajar dengan gaya mengajar latihan.

Berdasarkan hasil uji lanjut dengan menggunakan uji Tukey, dengan taraf signifikansi $\partial=0,05$ diperoleh harga $q_{\text {hitung }}$ sebesar $=3,247>q_{\text {tabel }}$ sebesar $=$ 2,86 maka dengan demikian $H_{0}$ ditolak.

$$
\text { Dengan demikian dapat }
$$
disimpulkan bahwa penelitian secara keseluruhan hasil hasil belajar lompat jauh yang belajar dengan gaya mengajar inklusi, lebih baik daripada yang belajar dengan gaya mengajar latihan secara keseluruhan teruji kebenarannya.

\section{KESIMPULAN, IMPLIKASI DAN SARAN}

\section{Kesimpulan}

Berdasarkan hasil penelitian, maka secara keseluruhan, yang belajar dengan gaya mengajar inklusi memberikan pengaruh yang lebih baik daripada yang belajar dengan gaya mengajar latihan terhadap hasil belajar lompat jauh.

\section{Implikasi}

Selama ini para dosen pendidikan jasmani dalam proses belajar mengajar menggunakan metode belajar yang pada umumnya dipergunakan oleh dosen-dosen bidang studi diluar pendidikan jasmani. Padahal bidang studi pendidikan jasmani 


\section{3| Eka Yanuar Putra}

Meningkatkan Hasil Belajar Lompat Jauh Melalui Gaya Mengajar Inklusi Bagi Mahasiswa Pjkr Fkip Universitas Suryakancana Cianjur mempunyai metode sendiri, yang lain dari

Edition Englewood New Jersey: metode-metode belajar yang ada, yaitu Preantice Hall, Inc. 2000.

yang disebut dengan gaya mengajar.

Ketepatan memilih menggunakan perlakuan gaya mengajar dan kesesuaian terhadap materi ajar, akan menentukan keberhasilan dosen di dalam proses belajar pendidikan jasmani, terutama yang berhubungan dengan belajar gerak. Seperti menggunakan gaya mengajar inklusi efekitif dipergunakan untuk mengajarkan lompat jauh. Dan selain itu menggunakan gaya mengajar tersebut dapat pula dipergunakan untuk mengajarkan materi pelajaran lainnya yang mempunyai karakteristik yang sama dengan gerakan lompat jauh.

\section{Saran-saran}

Sebaik kepada dosen disarankan agar menggunakan gaya mengajar inklusi untuk dijadikan sebagai pedoman mengajar dalam proses belajar mengajar pendidikan jasmani khususnya materi pelajaran yang mempunyai karakteristik sama dengan teknik lompat jauh.

\section{DAFTAR PUSTAKA}

Depdiknas. 2002. Ringkasan Kegiatan Belajar Mengajar. Jakara

Mosston, Muska\& Sara Ashworth.1994. Teaching Physical Education. Mac Millan College Publishing Company, Inc. USA. Dalam Jurnal Iptek Olahraga, Vol.10, No.3, September 2008: 216-231.

Joyce, Bruce, dan Weil, Marsha. 1980.

Model of Teaching. Second 